"This is an Accepted Manuscript of an article published by Taylor \& Francis in Construction Management and Economics on 13 Dec 2010, available online:

http://wwww.tandfonline.com/10.1080/01446193.2010.521760.”

\title{
INJURIES SUSTAINED BY YOUNG MALES IN CONSTRUCTION DURING DAY AND NIGHT WORK
}

\section{Abstract}

The increased participation of young workers in the construction industry is matched by a growing realisation of the vulnerability of these workers in terms of occupational injury and disease. The impact of organisational issues on injury rates for young workers is examined. This is an underresearched area where physical and psychological development influences have traditionally dominated. Data from the Australian Bureau of Statistics on labour force participation and work hours and data from the Queensland Injury Surveillance Unit on patients presenting at hospital emergency departments were used to examine incidence and severity of injuries sustained by young workers in construction on different shifts. Analyses indicated a different pattern of injury for young workers and workers outside this age category. Young workers were consistently more likely to be injured than all other workers, and this injury rate ratio increased significantly on night shift, suggesting that injury prevention strategies should consider the temporal pattern of work for young workers in construction.

Keywords: Injury, labour markets, occupational health and safety 


\section{INTRODUCTION}

As employment in the construction industry increases in Australia so too does the number of young people working in this industry. This increased participation is coupled with a growing realisation of the vulnerability of young people in terms of occupational injury and disease (ABS, 2006a). Traditionally, research on the increased risk of injury to young workers has focussed on individual factors resulting in important progress on the importance of physical and psychological development. More information is needed, however about organisational influences on injury rates for young workers. Researchers have recognised only recently that work hours may be a key variable determining injury rates for young workers (Howitz and McCall, 2005). At present, however, although there are compelling arguments about the influence on injury rates had by work hours, there is limited empirical evidence available to assess their importance, particularly in high risk industries such as construction. The research that is available suggests that workers are more likely to be injured during night work but this research has not directly examined young workers and it is not known whether they are more at risk during night work than their adult counterparts. This shortcoming is addressed in the current study by comparing injury patterns of young workers and adults in construction on day and night shift.

\section{YOUNG WORKERS IN AUSTRALIA}

A growing proportion of young people (for these purposes, defined as those aged between 19 and 24 years of age) are working in Australia. In the last three decades labour force participation rates for young workers in general have increased by nearly 10 percentage points (ABS, 2006b). The construction industry in particular has the higher proportional concentration of young people compared to the Australia population in the future when looking at projections of the age profile (ABS, 2001). This increased labour force participation has been matched by a growing concern about their risk of occupational injury. Young workers are now recognised as an especially high-risk 
group in terms of occupational injury and disease; they have an injury rate of 78 injuries per 1000 people (increasing to 91 injuries per 1000 people for young males), which is higher than all other workers (ABS, 2006a).

Looking at research examining organisational factors affecting the risk of occupational injuries to young workers in Australia, there is a general consistency that young workers face adverse working conditions resulting in a higher incidence of injury compared with adults (see for example NSW Commission for Children and Young People, 2005; Jobwatch, 2002; Mayhew and Quinlan, 2002; National Occupational Health and Safety Commission, 2000; Boufous and Williamson, 2003). These findings are consistent with most of the international literature (Dupre, 2000) but they fail to consider the impact of working hours and particularly night work on injury rates. They also tend to focus on young workers in the retail and hospitality industry. Although these are the industries where young people in general are most represented, young males are more likely to be found in high risk industries such as construction (ABS, 2006c).

\section{WORKING HOURS OF YOUNG WORKERS IN AUSTRALIA}

The primary work pattern in Australia continues to be traditional work schedules involving work during daylight hours. However, changes in regulations governing working time and trading hours in Australia have resulted in a significant and growing proportion of the workforce being employed on non-standard work patterns (ABS, 2006d). Furthermore, many Australian workers now have limited control over these work hours, which for many have increased in terms of the length of the work week and the length of the work shift (Peetz et al., 2003). Nonstandard work schedules have long since raised health and safety concerns amongst individuals, families and researchers (Healy, 2000). Australia now has some of the longest working hours in the world with shiftwork being used by a wider cross section of workers (Campbell, 2002). This is particularly the case when considering construction; the proportion of people in working 
more than 44 hours has increased by 11 percent since 1985 , which is one of the largest increases in any country (Van Wanrooy and Wilson 2006). Young workers are now more likely to be shiftworkers than any other age group in Australia (ABS, 2006d) and in construction working nonstandard work hours, including regular weekend work is now considered the norm (Lingard and Francis, 2004).

Looking at the health and safety effects of shiftwork, research indicates that shiftworkers experience a broader range of negative health symptoms more frequently and more severely than day workers (Folkard and Lombardi, 2006). There is a large body of evidence indicating that shiftworkers, in general, and nightworkers, in particular, suffer acutely and chronically impaired health and well-being including sleep problems headaches, anxiety, poor concentration, nervousness, mild depression, and mood disturbances, cardiovascular and musculoskeletal problems (Costa, 2003). Shiftwork is also linked with peptic ulcer disease and coronary heart disease (see Knutsson, 2003 for a review of this research).

The impact of working hours on young workers has been raised in the research literature but not examined in detail. For example, Loudoun and Allan (2008) examined the impact of work hours on injury rates of young workers and concluded that night work could increase the risk of injury for young workers. However, the focus of this study was the general working population, which is heavily concentrated in retail and hospitality and thus it is unclear how generalisable these findings are to male youths working in high risk industries such as construction.

Similar conclusions were drawn by, Horwitz and McCall (2005) in an examination of workers compensation claims. Their findings, however, need further investigation using alternative sources of data as workers' compensation data tend to only reflect injuries sustained by workers on standard, full time employment arrangements, which are not typical of the temporary, casual or short term contracts most young people are employed under. Furthermore, evidence suggests that young workers tend to have limited knowledge of their legal entitlements to workers compensation and they are less 
likely to make a claim when injured compared with other workers (Quinlan and Mayhew, 1999).

In summary, although there is a strong culture of long hours and weekend work in the construction industry in Australia, research to date has tended to look at the impact of the length of the work week on workers' health and safety. Little is known about the effects of the scheduling of work hours on injury rates, particularly for young people in the construction industry context.

The research described in this paper sort to address this gap by comparing the incidence and severity of injuries sustained by young workers and workers aged over 24 years in construction industry on day and night shifts. The primary study hypothesis, based on previous research, is that for all workers, when compared to conventional day shifts, working at night increases the risk of suffering occupational injuries but young workers are disproportionately at risk. The next section outlines the approach used to examine work hours and injury rates in the present study.

\section{METHOD}

\section{Study population and data sources}

Published and unpublished data from the Australian Bureau of Statistics are used for the study along with data collected by the Queensland Injury Surveillance Unit (QISU) on behalf of Queensland Health. These data are used to compare the injuries sustained by male construction workers of varying ages on day and night shift. The QISU data were collected by triage nurses from all injury presentations at 17 hospitals representing urban, rural and remote areas of Queensland. Together, these departments cover a quarter of the Queensland population with approximately 80 percent ascertainment. For each patient the triage nurse collected demographic information on age, gender, occupation and industry of employment (using the Australian Classification of Industries). Data was also recorded on the type of activity 
patients were engaged in when they sustained the injury. The triage nurse also collected information on the time and date the injury occurred, as well as recording the degree of injury severity.

The study considered data recorded for males between 1999 and 2006. The dataset was restricted to males injured while undertaking paid work in construction, be they employees or self-employed. Females were deleted from the data set because previous research has found gender differences in injury rates (Loughlin and Frone, 2004) and it was not possible to examine females separately owing to low representation in the dataset (less than 2 percent). The underrepresentation of women in construction has been well documented and thus their low representation in the QISU data did not suggest any biases in the study. These restrictions resulted in 5162 recorded injuries; 1545 of these injuries were from male workers aged 24 years and under.

For the purpose of this study an interval scale of 1 to 5 for injury severity was used, based on the five categories used by the triage nurse to record severity of injury. Injuries were classified as occurring either during the day shift, 6am to $5 \mathrm{pm}$, or the night shift, $5 \mathrm{pm}$ to $6 \mathrm{am}$; these shift times were chosen to remain consistent with $A B S$ conventions.

Unpublished data from the ABS on working time arrangements were used to supplement the QISU data. In November 2003, additional data was collected from 25457 dwellings as a supplement to the ABS monthly Labour Force Survey (LFS) on the number of hours spent at work in the week surveyed; the number of workers who performed shiftwork; and the type of shiftwork undertaken. These data were used to control for the possible influence of uneven work patterns across the day, and across different age groups, on the frequency of work-related injuries. The 2003 data were chosen as this year represents a reasonable mid-way point during the collection period, 1999 to 2006 for the QISU injury data. 
The ABS Labour Force Survey asked respondents to indicate whether they performed any shift work at any time in the 4 weeks prior to the survey and how many hours they worked in their main job. Those who indicated that they worked shifts were asked the type of shift system they normally work. The alternative responses were: (i) rotating shifts that change periodically; (ii) regular morning shift (work between 6.00 am and 12.00 pm); (iii) regular afternoon shift (work between $12.00 \mathrm{pm}$ and $5.00 \mathrm{pm}$ ); (iii) regular evening, night or graveyard shift (work between v between $5.00 \mathrm{pm}$ and 6.00 am); or, (iv) other (split shift, on-call, irregular and other).For the purpose of this study workers were divided into day (respondent doesn't work shiftwork or works regular morning, afternoon or other shifts) and night work (regular, evening, night and graveyard shifts). Workers, who indicated that they worked rotating shifts that changed periodically, split shifts or on-call, were divided equally between day and night work.

The study also made use of published data from the ABS to evaluate the representativeness of the injury data and thus the appropriateness of supplementing the sample data with national ABS data. This was achieved by comparing industry and demographic characteristics of the hospitals districts in the study with characteristics of the nation as a whole. Data for these comparisons was sourced from the 2001 National Census (ABS, 2001). The Census provided data for Australia as a whole and for individual regions defined by electoral districts. The electoral districts in the catchment areas of the hospitals in the study were combined into one region and the distribution of persons in this region compared with the distribution of person in Australia by gender, age and industry. These data are shown in Table 1 and discussed in the results section. It should be noted that these Census data use set age ranges that differ from the age ranges used in this ABS Labour force data and the QISU data. However, as the purpose of these comparisons was to examine comparability between the hospital districts and the Australian population in general, these differences do not present any biases for analyses using the QISU and the ABS data. 
Statistical analyses

To examine relationships between injury frequency, age and work hours, a visual representation of injuries by time of day was first undertaken by plotting data on a graph (see Figure 1). The calculation of crude occupational injury ratios then followed. This approach allowed a comparison of Injury ratios for work-related injuries among youth and adult workers performing night work with those performing conventional day schedules. Two injury ratios were calculated (see Table 2). First, the total number of employees at work during the day and night (taken from the unpublished ABS data) was expressed as a percentage and divided by the percentage of injuries sustained during these hours. This ratio is labelled 'injuries to employees' in Table 2. Second, the number of hours spent at work during the day and night (taken from the unpublished ABS data) was expressed as a percentage and divided by the percentage of injuries sustained during these hours. This ratio is labelled 'injuries to work hours' in Table 2. The first measure provides a conventional assessment of the likelihood of injury for employees of different ages working during the day or at night. The second ratio measure is superior because many employees do not work full-time, particularly young workers. The work hours to injury ratio measure thus provides a more realistic gauge of the likelihood of injury for workers at different times of the day.

Multivariate analyses were employed where possible to control for the possible influence of employment type and occupation. It was not possible to use multivariate analyses for frequency of injury but it was possible to examine severity of injury as this variable was scored on a five-point scale devised from the patient's triage category. When a patient presented at the accident and emergency department, the triage nurse classified the injury into one of five categories: resuscitation, emergency, urgent, semi urgent or non urgent. By attaching a score to these categories - (resuscitating equals one, emergency equals two urgent equals three, semi urgent equals four and non urgent equals five) an interval index of injury acuity or severity was conducted. This 
index was then used to explore the possibility that youths sustain more injuries than workers outside this age category, but these injuries are less severe and thus their injuries are of less concern. This approach provides a more critical picture of the relationship between age and work hours.

\section{RESULTS}

The distribution of persons in the study region and Australia by age are summarised in Table 1. As can be seen, the characteristics of individuals working in the study region were very similar to the characteristics of the Australian population in terms of age and gender structure. The table illustrates that there are no major differences between the study region and the Australian population that could potentially influence the spread of employment and working hours in the sample data. Thus it seems reasonable to combine the national data with the sample data to create injury ratios.

\section{INSERT TABLE 1 ABOUT HERE}

\section{Injury frequency}

A visual representation of the pattern of injury reported by different age groups is shown in Figure 1.This figure was derived using a combination of unpublished ABS data and QISU data with the proportion of day and night workers plotted against the proportion of injuries sustained during the day and night separately for each age group. The shaded lines represent the percentage of workers performing work during the day and night by age group. The non-shaded lines represent the percentage of injuries sustained during day and night groups by age.

Using this simple visual representation, the pattern of injury for youths and adults looks very similar with the highest incidence of injury occurring during the day when the majority of work hours are performed. The elevated risk of injury associated with night 
work is evident in the figure - with these hours accounting for less than 5 percent of work hours across all workers but between 10 and 15 percent of injuries - but there are not stark differences between the groups.

\section{INSERT FIGURE 1 ABOUT HERE}

A different picture, emerges, however, when the number of hours spent at work (and thus the number of hours exposed to workplace hazards) and the proportion of dayand night-workers represented by different age groups are examined. This information is illustrated in Table 2.

Column 2 shows the proportion of injuries sustained by different groups on day and night shift; column 3 shows the proportion of day and nightworkers in different age groups. Looking at these two columns together, they indicate that male youths have an increased risk of injury on the night shift. Youths account for 15 percent of all male nightworkers, yet they are responsible for 24 percent of injuries presented on these shifts. This contrasts with workers aged over 24 years where, for example, male construction workers aged 25-34 years account for 37 percent of nightworkers but only 34 percent of injuries. So, whereas the percentage of injuries sustained on night shift is less for workers aged over 24 years the pattern is reversed for workers aged 19-24 years.

Column 4 of Table 2 reports percentage of injuries divided by percentage of employees at work at different times of the day. This calculation is expressed as a ratio of injuries to employees with the highest ratio of 1.57 being for male youths on night shift, which contrasts with all other workers who have a ratio of less than 1.

The fifth column of the table report the total hours worked by employees on day and night work. These hours are expressed as a percentage of total hours by age. Although male youths represent 24 percent of all injuries to males on night work, they are 
responsible for only 16 percent of the actual hours worked on these shifts. This results in an injury to hours ratio of 1.48 for male youths, which is 1.5 to 2 times higher than their adult counterparts. The injury to hours ratio and is lower on night shift for all workers except for those at either end of the workforce - 19-24 years and 45 years and older.

\section{INSERT TABLE 2 ABOUT HERE}

\section{Severity of Injury}

To examine the relationship between severity of injury, age and work hours, analysis of covariance (ANCOVA) was used. Prior to the analysis, data were examined for missing data and violations of the assumptions of ANCOVA, including homogeneity of slopes. Any cases that presented missing data for the variables of interest were deleted, leaving 3542 cases for analysis.

In the ANCOVA, age and work hours (day, night work) were entered as factors and occupation (using Australian Standard Classification of Occupations Level 2 definitions) and employment type (employed, self employed, other) as covariates. Results revealed no significant relationships between occupation and severity of injury or employment type and severity of injury. Age and work hours were not related to severity of injury and there was no significant interaction between age and work hours.

\section{CONCLUSIONS}

The purpose of this study was to examine temporal patterns of work injuries for young workers in construction. The findings provide strong evidence that work hours are linked to injury frequency for young male workers in the Australian construction industry. Results revealed a different pattern of injury for young workers and workers aged over 24 years. In general, young construction workers have an increased risk of 
overall injury at all times of the day compared with workers aged over 24 . This injury rate increased significantly on night shift, particularly when work hours were included in the analyses. A reverse pattern was evident for workers aged over 24 years once work hours were considered. There were no significant differences between the age groups for severity of injury on day or night shift indicating that the increased injuries sustained by youths on night work were of equal severity to the injuries they sustained on day shift and to the injuries sustained by their co-workers aged over 24 years.

In combination these results support previous research that young workers in general are at an elevated risk of work related injury. The finding that this elevated risk extends to young male shiftworkers employed in a high-risk industry extends previous research, which has traditionally focussed on the general working population, usually in low risk industries such as retail and hospitality (Loughlin and Frone, 2004). Expanding research to include these workers is significant as employment in the youth labour market is increasingly gender specific with young males working in high risk industries. Indeed, young males in the 20-24 year old bracket are more likely to be employed in construction than any other industry in Australia and their participation in this industry has grown by 6 percentage points in the last five years (ABS, 2006d).

The findings also support previous research emphasising the risks associated with working in high-risk workplaces for young males and adds to research emphasising the importance of training and supervision in improving work safety for these workers. For example, previous research suggests that young people in general require more supervision owing to their limited work experience, poor risk assessment, vulnerability to peer or work pressure and sensation seeking (Castillo, 1999; Loughlin and Frone, 2004). This is especially relevant for young males in construction owing to inconsistencies in the physical and cognitive development. Although these workers often appear to be physically mature, evidence indicates that they still often lack the full adult decision-making and cognitive functioning required to make wise work-safety judgments (Beharie, 2003). Furthermore, research has found that for many young 
workers, their underdeveloped communication and social skills and lack of empowerment and self-confidence, prevents them from performing safe practices learnt through training programs or in their employment and reporting accidents, raising concerns about the safety to supervisors and resisting pressure to perform unsafe acts by more experienced or senior staff (Linker Miller, Freeman, Burbacher, 2005; Schulte, Stephenson, Okun, Palassis, Biddle, 2005).'

The main contribution of this study, however is to highlight the need to broaden the variables of interest in future research and interventions aimed at improving occupational health and safety on construction sites for young workers. Previous research has largely focussed on the individual as the unit of analysis, identifying within-individual determinants of injuries. Seldom explored are the patterns of work hours for young people and how these patterns influence overall risk of injury. As such the findings of this study broaden previous work to include organisational variables. The findings suggest that the work scheduling should also be considered when looking at determinants of work injuries amongst young people and more research is needed on the interaction between known determinants of work injuries such as shiftwork and young workers' physical and cognitive makeup.

This research has identified a different injury pattern for young workers with night work being particularly problematic. More focussed research, however is needed to explain why work schedules impact differently on young people. Previous research suggests that young people have different eating and drinking habits and sleep patterns compared with more mature workers. For example, healthy eating is often a low priority or not practiced amongst teenagers and young adults (These lifestyle factors may contribute to injury rates at night in young people as evidence suggests that irregularities in food intake amongst shiftworkers are associated with gastrointestinal complaints, nutritional deficiencies, fatigue and alertness (Duchon \& Keran, 1990; Rutenfranz, Haider, \& Koller, 1985).Similarly, sleep patterns may contribute to higher injury rates for young people owing to temporary changes in their sleep requirements 
as they enter adulthood (Dahl, 1999; Wolfson and Carskadon, 1998). However, it is unclear how changes in sleep interact with shifts; more research is needed to the combined effect of these variables. Looking at the results of this study, although development is typically not complete until young people are well into their twenties (Beharie, 2003), altered sleep patterns and eating schedules are likely to be more relevant for younger workers (19 and 20 year olds) in the age group examined than they are for workers at the higher end of the group (22 to 24 year olds); these workers are more likely to follow patterns consistent with more mature workers. Either way the lack of experimental design in this study precludes drawing causal inferences about the effect of night work on injury rates for young people. However the research is ongoing and these variables point to variables of interest to investigate further. Future evaluations of injury rates for young workers in construction will utilize a robust multiple baseline experimental design to enable the impact of work hours to be rigorously evaluated. The findings need to be viewed in light of several methodological limitations. The reliance on emergency data means that injuries, particularly acute injuries are more likely to be captured and, as a result, diseases caused by exposure to hazardous substances, especially those with long latency periods are unlikely to be represented in the data. Similarly injuries treated by local doctors and private medical practitioners and specialists who admit patients directly to hospitals rather than through the emergency department will not be captured. To overcome these problems, future research should couple emergency data with workers compensation data and other national injury data to allow a fuller picture of occupational injuries requiring a wider range of employment types, injuries and medical intervention to emerge.

Additionally, the lack of information on rostering and overtime schedules in the ABS data means that inconsistencies related to work hours are likely to exist. For example, it is not clear from the data whether work on split-shift, on-call and rotating work hours was performed on day-shift or night-shift. However, as the number of workers who reported working on these arrangements represents less than one percent of all construction workers, it is unlikely to have had a significant bearing on the results. 
Similarly, the majority of workers indicated that they didn't perform overtime and there is no evidence to suggest that young workers performed more overtime than workers outside this age category but it is still not known when the overtime was performed and by whom. It is also possible that different work was performed at night, although once again there is no evidence to suggest that this work is more likely to be done by young workers or workers with limited experience.

Despite these limitations, the approach used in the existing study does provide greater surety in the findings about the OHS risks of young workers in construction than much of the previous research and forms a solid platform for future research using more multivariate methods of analysis. The use of large-scale data sets was a strength of this study thereby increasing the generalisability of the findings. The method used to gather the hospital emergency data also adds to the construct validity of the study. Data were collected by triage nurses and the time of the injury presentation, which minimises problems with interpretation and accuracy of recall found in many self report studies. Furthermore, data were gathered on all injuries - including non compensable and minor injuries - and all employment arrangements - including casual, temporary and self employment. Restrictions on injury type, absence from work and permanency of employment in most workers compensation schemes means that many workers and injuries are not captured by these data bases (Boufous and Williamson, 2003). This criticism is particularly relevant to research on injuries in the construction industry because self employment, temporary, contract and casual work are increasingly the norm (Lingard and Francis, 2004). Employment that leaves workers with less job security (such as highly casualised, transitory or unlawful employment relationships) is also likely to result in workers failing to report injuries or hazards or lodge claims for compensation (Fishback and Kantor; 2000).

In summary, this research indicates that young workers in construction have a unique temporal pattern of work injuries and, as such, they require special consideration and further research to determine why their injury pattern is different to other workers and to 
inform injury prevention strategies. These findings should be of concern to researchers, employers and those involved in policy development aimed at minimising injuries at work and improving the work experience of tomorrow's workforce. Although some statutory limits on the hours that can be worked for worked aged under 19 years have been introduced in some states in Australia in recent years, the findings here suggest that questions also need to be raised about the capacity of workers aged 20 to 24 years to remain active in the workforce as they age.

\section{REFERENCES}

Australian Bureau of Statistics (2001) 2001 Census of Population and Housing. Canberra (CDATA2001).

Australian Bureau of Statistics (2006a) Work-related Injuries, Australia. Canberra (Cat. No. 6324.0).

Australian Bureau of Statistics (2006b) The Labour Force, August 2006. Canberra (Cat. No.6202.0).

Australian Bureau of Statistics (2006c) 2006 Census of Population and Housing. Canberra (CDATA2006).

Australian Bureau of Statistics (2006d) Working Time Arrangements, Australia. Canberra (Cat. No. 6342.0).

Beharie N. (2003). New kid on the block. OH\&S Canada, 19(4): 30-38.

Boufous, S. \& Williamson, A. (2003) Work-related Injury, NSW Hospitalisation and Workers Compensation Datasets: A Comparative Analysis. ANZ Public Health, 27(3), 352-357.

Campbell, I. (2002) Extended Working Hours in Australia. Labour and Industry, 13(1), 91-110. 
Castillo, D.N. (1999) Occupational Safety and Health in Young People, in Barling J \& Kelloway, E., K. (eds) Young Workers: Varieties of Experience, American Psychological Association, Washington DC.

Costa, G (2003) Shiftwork and occupational medicine: An overview. Occupational Medicine, 53(2) 83-88.

Dahl, R. (1999). The Consequences of Insufficient Sleep for Adolescents. Phi Delta Kappan. 345-359.

Duchon, J.C. and Keran, C.M., (1990). Relationships among shiftworker eating habits, eating satisfaction, and self-reported health in a population of U.S. miners. Work \& Stress, 4 2, pp. 111-120.

Dupre, D. (2000) Accidents at Work in the EU. Statistics in Focus: Population and Social Conditions (Cat. No: CA-NK-00-004-EN-I). Eurostat, Luxembourg.

Folkard, S., and Lombardi, D. A. (2006) Modelling the impact of the components of long work hours on injuries and "accidents". American Journal of Industrial Medicine, 49(11), 953-963.

Fishback, P.V and Kantor, S.E Chicago (eds.) (2000) A Prelude to the Welfare State: The Origins of Workers' Compensation, University of Chicago Press, Pp. xiii, 316. Healy, E. (2000) The Shift to Long Working Hours: A Social and Political Crisis in the Making. People and Place, 8(1): 38-51.

Howitz, B.I. \& McCall, B.P. (2005) Occupational Injuries among Rhode Island Adolescents: An Analysis of Workers' Compensation Claims, 1998-2002. Occupational and Environmental Medicine. 47(5), 473-481. Job Watch (2002) Children at Work? Policy Challenges and Choices for Victoria. Job Watch, Melbourne.

Knutsson, A. (2003) Health disorders of shiftworkers. Occupational Medicine, 53(2) 103-108. 
Lingard, H. \& Francis, V., (2004) The work-life experiences of office and site-based employees in the Australian construction industry. Construction Management and Economics, 22: pp. 991-1002.

Linker D, Miller ME, Freeman KS, Burbacher T. (2005). Health and safety awareness for working teens: developing a successful statewide program for educating teen workers. Family and Community Health, 28(3): 225-238.

Loudoun, R and Allan, C. (2008) The effect of time of day on injury patterns amongst adolescents in Australia. Applied Ergonomics, 39(5), 572-579.

Loughlin, C. \& Frone, M.R. (2004) Young Workers Occupational Safety, in Barling, J. \& Frone, M.R. (eds) The Psychology of Workplace Safety, American Psychological Association, Washington, 107-127.

Mayhew, C. \& Quinlan, M. (2002) Fordism in the Fast Food Industry: Pervasive Management Control and Occupational Health and Safety risks for Young Temporary Workers. Sociology of Health and IIIness, 24(3), 261-285.

National Occupational Health and Safety Commission (2000) Occupational Health and Safety Issues for Young Workers in the Fast Food Industry. Ausinfo, Canberra.

NSW Commission for Children and Young People (2005). ATC - Children at Work. NSW Commission for Children and Young people, <http://www.kids.nsw.gov.au/kids/resources/publications/askchildren.cfm>.

Peetz, D., Townsend, K., Russell, B., Houghton, C., Fox, A., and Allan, C., (2003) Race Against Time: Extended Hours in Australia. Australian Bulletin of Labour, 29 (2), $126-$ 142.

Quinlan, M. \& Mayhew, C. (1999) Precarious Employment and Workers' Compensation. International Journal of Law and Psychiatry, 22, 491-520.

Rutenfranz, J, Haider, M, Koller, M (1985), "Occupational health measures for night and shift workers", in Folkard, S (Eds), Hours of Work. John Wiley, Chichester, pp.199-210. 
Schulte PA, Stephenson CM, Okun AH, Palassis J, Biddle E. (2005). Integrating occupational safety and health information into vocational and technical education and other workforce preparation programs. American Journal of Public Health, 95(3): 404411.

Van Wanrooy, B. and Wilson, S. (2006), Convincing the Toilers? Dilemmas of Long Working Hours in Australia. Work Employment and Society, 20(2): 349-368.

Wolfson, A.R. \& Carskadon, M.A. (1998). Sleep Schedules and Daytime Functioning in Adolescents. Child Development, 69, 875-887. 
Figure 1

Proportion of injuries and hours worked by age and shift

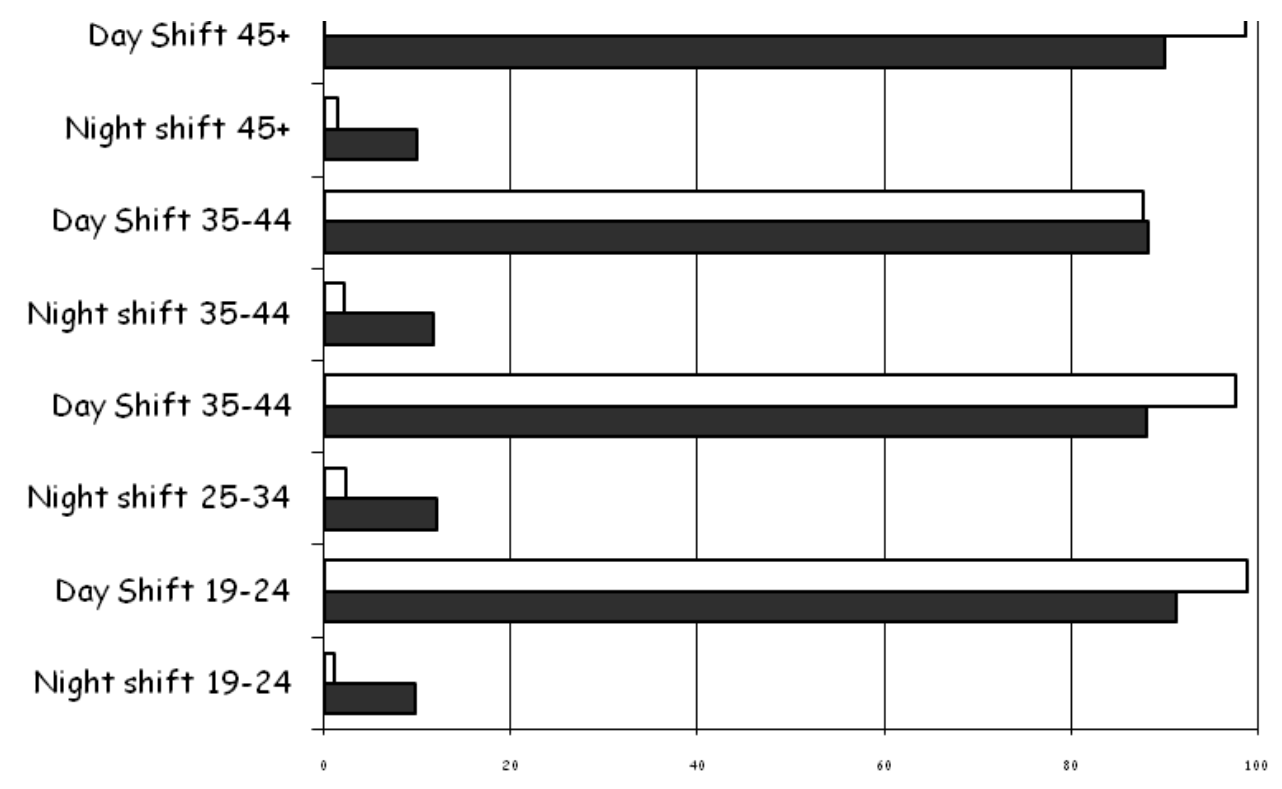

$\square \%$ of age category $\quad \square \%$ of iṇjuries 


\section{Table 1}

Distribution of industry, sex and age group across Australia and study region (2001)

\section{Australia (\%) Study Region (\%)}

\section{Gender}

$\begin{array}{lcc}\text { Female } & 50.6 & 50.0 \\ \text { Male } & 49.4 & 50.0 \\ \text { Total } & 100 & 100\end{array}$

\section{Age}

0-14

19.8

20.8

15-34

27.1

29.1

$35-49$

22.1

22.3

$50-64$

17.7

17.1

65-74

6.9

5.8

$75+$

6.4

5.0

Source: ABS 2001 Census 
Table 2 Distribution and ratio of injuries and employees and hours worked

\begin{tabular}{|c|c|c|c|c|c|c|c|c|c|c|c|c|c|c|c|}
\hline \multirow[b]{2}{*}{ Males } & \multicolumn{3}{|c|}{$\begin{array}{l}\text { Distribution of } \\
\text { Injuries, } \\
\text { Selected QId } \\
\text { Hospitals, } \\
\text { 1999-2006 (\%) }\end{array}$} & \multicolumn{3}{|c|}{$\begin{array}{l}\text { Distribution of } \\
\text { Employees, } \\
\text { Australia } 2003(\%)\end{array}$} & \multicolumn{3}{|c|}{$\begin{array}{l}\text { Ratio of Injuries to } \\
\text { Employees }\end{array}$} & \multicolumn{3}{|c|}{$\begin{array}{l}\text { Distribution of work } \\
\text { hours, } \\
\text { Australia } 2003(\%)\end{array}$} & \multicolumn{3}{|c|}{$\begin{array}{l}\text { Ratio of Injuries to } \\
\text { work hours }\end{array}$} \\
\hline & Day & Night & Total & Day & Night & Total & Day & Night & Total & Day & Night & Total & Day & Night & Total \\
\hline $19-24$ & 31 & 24 & 30 & 25 & 15 & 25 & 1.22 & 1.57 & 1.20 & 23 & 16 & 23 & 1.35 & 1.48 & 1.32 \\
\hline $25-34$ & 31 & 34 & 31 & 27 & 37 & 27 & 1.14 & 0.92 & 1.15 & 28 & 32 & 28 & 1.12 & 1.04 & 1.13 \\
\hline $35-44$ & 21 & 25 & 22 & 21 & 27 & 22 & 0.99 & 0.92 & 1.01 & 22 & 32 & 22 & 0.96 & 0.78 & 0.97 \\
\hline $45+$ & 17 & 17 & 17 & 26 & 21 & 26 & 0.65 & 0.81 & 0.65 & 27 & 19 & 27 & 0.63 & 0.88 & 0.63 \\
\hline Total & 100 & 100 & 100 & 100 & 100 & 100 & & & & 100 & 100 & 100 & & & \\
\hline
\end{tabular}

